\title{
Partial Ventricular Atrioventricular Canal Aged about a Case
}

\author{
C. A. Thiam¹, S. Sidibé2, Y. Camara1, S. Coulibaly², A. K. Sacko², H. O. Bâ3, M. Diakite², S. Diallo4, \\ I. Sangaré ${ }^{3}$, S. J. B. Tougouma ${ }^{5}$, M. Konaté6, S. Sidibé4, A. Keita ${ }^{4}$, N. Sidibé ${ }^{3}$, S. Mariko7, M. Sako², \\ I. Menta ${ }^{3}$, B. Diallo 2
}

${ }^{1}$ Cardiology Department, Hospital Kati, Bamako, Mali

${ }^{2}$ Cardiology Department, Point “G” Hospital University Center, Bamako, Mali

${ }^{3}$ Cardiology Department, Gabriel TOURE Hospital University Center, Bamako, Mali

${ }^{4}$ Cardiology Department, Mother Hospital Child "le luxembourg”, Bamako, Mali

${ }^{5}$ Higher Institute of Health Sciences, Nazi Boni de Bobo Dioulasso University, Bobo Dioulasso, Burkina Faso

${ }^{6}$ Cardiology Department, Hospital Mali, Bamako, Mali

${ }^{7}$ Cardiology Department, Hospital Tombouctou, Tombouctou, Mali

Email: mentasomonosso@yahoo.fr

How to cite this paper: Thiam, C.A., Sidibé, S., Camara, Y., Coulibaly, S., Sacko, A.K., Bâ, H.O., Diakite, M., Diallo, S., Sangaré, I., Tougouma, S.J.B., Konaté, M., Sidibé, S., Keita, A., Sidibé, N., Mariko, S., Sako, M., Menta, I. and Diallo, B. (2019) Partial Ventricular Atrioventricular Canal Aged about a Case. World Journal of Cardiovascular Diseases, 9, 51-55.

https://doi.org/10.4236/wjcd.2019.91006

Received: January 2, 2019

Accepted: January 25, 2019

Published: January 28, 2019

Copyright (๑) 2019 by author(s) and Scientific Research Publishing Inc. This work is licensed under the Creative Commons Attribution International License (CC BY 4.0).

http://creativecommons.org/licenses/by/4.0/

\begin{abstract}
Introduction: The partial ventricular atrioventricular canal is a congenital heart malformation of the ostium primum type of variable surface that can reach the single atrium where the interatrial septum is no more than a cephalic muscular vestige attached to the roof of the atrium. His diagnosis at the age of 73 is not a common situation. The interest of this clinical case that we report lies in the peculiarity of its mode of discovery and its evolution under medical treatment. Observation. He was a 73-year-old patient with no known cardiovascular risk factor and has since been at about 18 years of age with heart failure syndrome with progressive dyspnea, cough and edema of the lower limbs, but never explored for lack of financial means, and the evolution was enamelled by episodes of cardiac decompensation, the last of which dated back to $03 / 07 / 2018$ justifying a hospitalization in our service. Cardiac ultrasound shows a partial atrioventricular canal. The care was medical. Conclusion: The atrioventricular canal is a congenital heart disease complex of poor prognosis.
\end{abstract}

\section{Keywords}

Partial Ventricular Atrioventricular Canal, Heart Disease, Mali

\section{Introduction}

The partial ventricular atrioventricular canal is a cardiac malformation. In al- 
most all cases, the elementary anomaly of the atrioventricular valve, tripled by "mitral cleft", is associated with it while the right atrioventricular valve is either normal, tricuspid, or lacunar between its anterior and septal valves. It accounts for about $3 \%$ of all cardiac malformations [1] [2]. It is present in two cases out of 10,000 live births. Both sexes are also affected, with a slightly higher frequency among women ( $\mathrm{F} / \mathrm{H}$ ratio at 1.3$)$. The diagnosis of a partial ventricular atrioventricular canal at age 73 is not a common situation.

\section{Observation}

We report the case of a 73-year-old patient who consulted for a global heart failure syndrome. He has no known cardiovascular history, but has been symptomatic of a global heart failure since the age of 18 with periods of remission. The initial assessment, in particular the electrocardiogram and the Doppler echo, could not be performed for financial difficulties. The current episode dates from 03/07/2018 marked by a dyspnea of increasing evolution, a cough with whitish sputum and edema of the lower limbs. The cardiovascular examination found irregular heart sounds at times, a $3 / 6$ systolic murmur at the mitral focus and a blood pressure of $110 / 80 \mathrm{mmmHg}$. The arterial distension was well perceived. Pulmonary auscultation revealed cerebral crackles at both pulmonary bases. The abdominal examination found painful hepatomegaly associated with hepatic jugular reflux. The biological assessment (glycemia, serum creatinine, blood ionogram, TSHus, HIV serology) was unremarkable and the blood count and count showed anemia at $7 \mathrm{~g} / \mathrm{dl}$. The electrocardiogram recorded complete arrhythmia with atrial fibrillation associated with a straight bundle of branches (Figure 1). The frontal chest X-ray showed cardiomegaly associated with vascular redistribution to the apex (Figure 2).

The cardiac Doppler echo revealed a large axis of the sternal axis with a mitral cleft associated with severe mitral insufficiency (Figure 3). In four cavities, a large ostium primum interatrial communication was shown (Figure 4). This interatrial communication and bi-atrial dilation were best seen in the xiphoidal section (Figure 5).

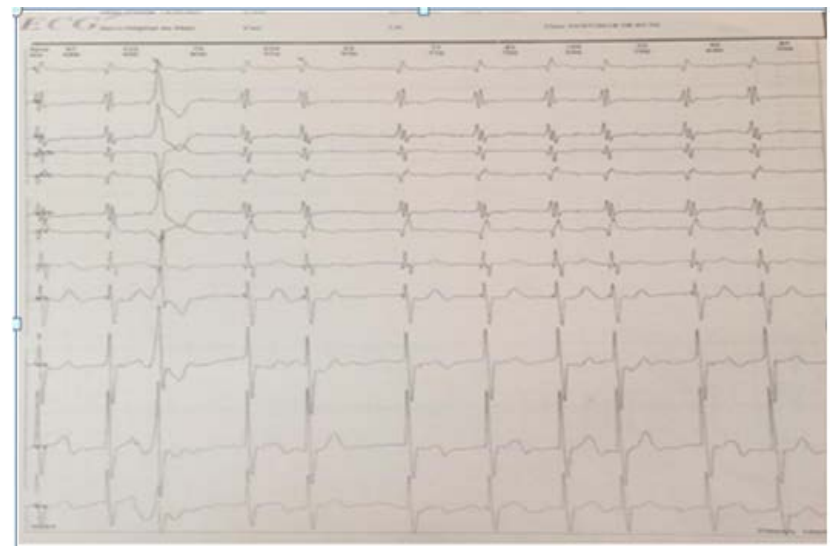

Figure 1. Electrocardiogram. 


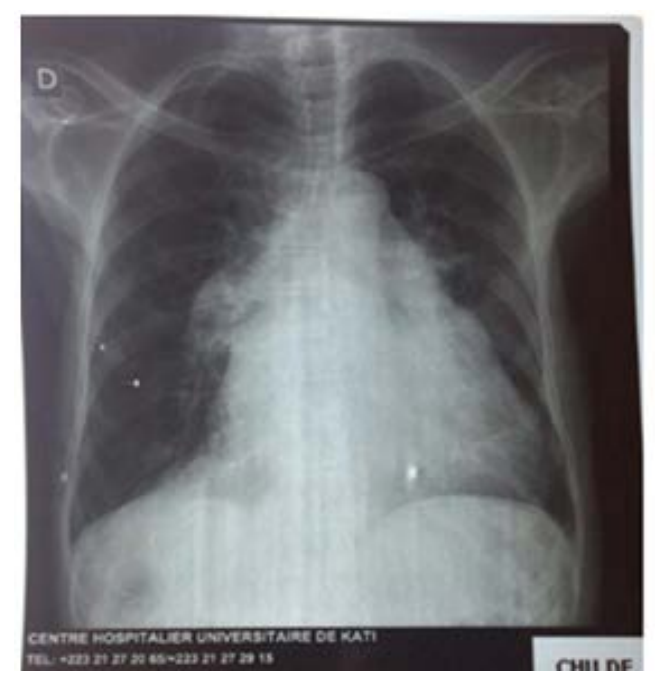

Figure 2. Frontal chest X-ray.

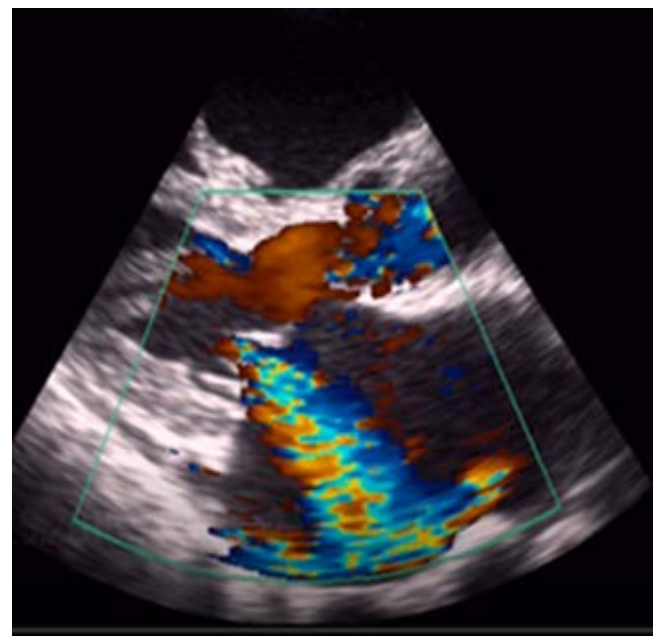

Figure 3. The cardiac Doppler echo revealed a large axis of the sternal axis with a mitral cleft associated with severe mitral insufficiency.

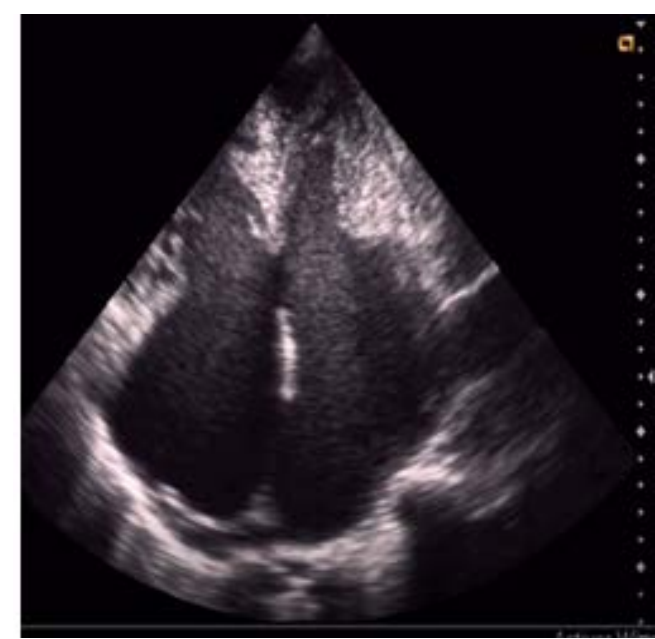

Figure 4. Four cavity cut showing biatrial dilatation and interatrial communication. 


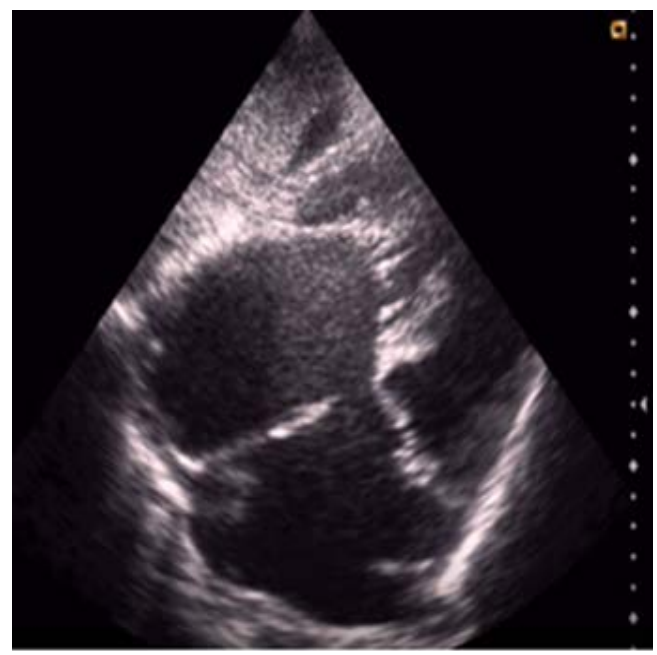

Figure 5. Costal cut showing ostium primum inter atrial communication.

The evolution was marked by the regression of the symptomatology of cardiac insufficiency under a conventional treatment associating a reduced diet, of diuretic, of the inhibitor of conversion enzyme and of an anti vitamin $\mathrm{K}$ and a transfusion of 3 pockets fresh blood. The treatment was medical due to lack of technical platform and the high cost of evacuation to a more equipped center outside the country.

\section{Discussion}

The peculiarity of this clinical case is mainly related to its mode of symptomatic discovery at the age of 18 years. According to literature, tolerance is generally excellent during the first years of life. It is very rare but possible that a massive left atrioventricular leak puts the patient in cardiac insufficiency so obvious as to wonder about the operative indication from the earliest childhood. But more often and more rapidly than in other atrial septal defects, in the course of the second childhood or adolescence, we end up seeing heart failure or rhythm disturbances, which leads to the operative indication [3]. The diagnosis of the partial atriventricular canal was evoked in front of a global cardiac insufficiency, suspected from the results of the electrocardiogram and the radiography of the frontal pulmonary and confirmed by the Doppler echo as described in the works of Calabrò [4] We conclude that this heart failure should prompt us to pay more attention to the search for aged congenital heart disease in elderly patients. The evolution was marked by the regression of the symptomatology of heart failure until today under medical treatment.

\section{Conclusion}

The partial atrioventricular canal is manifested very early by global heart failure. Its prognosis is better until adolescence and rare in adulthood. The treatment is surgical. 


\section{Conflicts of Interest}

The authors declare no conflicts of interest regarding the publication of this paper.

\section{References}

[1] Flyer, D.C. (1992) Endocardial Cushion Defects. In: Fyler, D.C., Ed., Nadas' Pediatric Cardiology, Hanley \& Belfus, Inc., Philadelphia, 577-589.

[2] Ferencz, C., Loffredo, C.A., Correa-Villasenor, A. and Wilson, P.D., Eds. (1997) Genetic and Environmental Risk Factors of Major Cardiovascular Malformations: The Baltimore-Washington Infant Study 1981-1989. Futura Publishing Company, Inc., Armonk.

[3] Kim, J.S., Viragh, S., Moorman, A.F., Anderson, R.H. and Lamers, W.H. (2001) Development of the Myocardium of the Atrioventricular Canal and the Vestibular Spine in the Human Heart. Circulation Research, 88, 395-402.

https://doi.org/10.1161/01.RES.88.4.395

[4] Calabrò, R. and Limongelli, G. (2006) Complete Atrioventricular Canal. Orphanet Journal of Rare Diseases, 1, 8. https://doi.org/10.1186/1750-1172-1-8 